\section{Comparison between Rose Bengal Plat Test and Competitive Enzyme Linked Immunosorbent Assay to Detect Bovine Brucellosis in Kigali City, Rwanda}

\section{Rosine Manishimwe $^{1 *}$, Julius Ntaganda ${ }^{1}$, Richard Habimana $^{1}$, Kizito Nishimwe ${ }^{1}$, Maurice Byukusenge ${ }^{1}$, Fausta Dutuze ${ }^{1}$, Jean de Dieu Ayabagabo', Umurerwa Lydia $^{2}$ and Jean Claude Rukundo ${ }^{2}$}

${ }^{1}$ School of Animal Sciences and Veterinary Medicine, University of Rwanda -Nyagatare Campus, Rwanda

${ }^{2}$ Unit of Veterinary Services, Rwanda agriculture Board, Ministry of Agriculture and Animal Resources, Rwanda

\begin{abstract}
Bovine brucellosis is a zoonosis known to be a major public health hazard of great economic importance worldwide. Its detection in cattle is frequently done using serological tests like Rose Bengal Plate Test (RBPT) and Competitive- Enzyme Linked Immuno Sorbent Assay (C-ELISA). Few studies have been conducted to compare the serological tests most commonly used to detect bovine brucellosis in Rwanda.

The study was conducted in Kigali city, the capital of Rwanda, to compare RBPT and C-ELISA test in detection of bovine brucellosis. Two thousands and seventeen (2017) cattle serum samples were collected, from 157 randomly selected farms, and were tested for bovine brucellosis using RBPT and C-ELISA.

The overall prevalence given by RBPT $(2.03 \%)$ was greater than the prevalence given by C-ELISA (1.7\%). The study revealed that even if the observed difference between prevalence given by RBPT and the prevalence given by C-ELISA was significant ( $p$-value $<0.05$ ), the agreement between the two tests has been found excellent with a Kappa of 0.92

The study has provided information on the agreement of the two serological tests commonly used to detect bovine brucellosis in Kigali. It is known that the agreement between two tests varies depending on the prevalence, thus there is a need for the study to be extended to the other provinces of Rwanda where the prevalence is probably different to the prevalence in Kigali.
\end{abstract}

Keywords: Brucellosis; ELISA; Rose Bengal Plate Test; Tests Agreement; Rwanda

\section{Introduction}

Bovine brucellosis is an infectious and contagious disease usually caused by Brucella abortus, less frequently by Brucella melitensis, and occasionally by Brucella suis [1]

It is a major zoonosis with an important economic and public health impact. Humans are infected either by direct contact with infected animals or by ingesting contaminated products, mainly unpasteurized dairy products [2]. Brucellosis in humans is characterized by a febrile flu-like syndrome, frequent chills, headaches and general weakness [3].

In cattle, it is usually spread by the vaginal discharge of an infected cow or an aborted foetus. Infected breeding bulls can transmit the disease to cows at the time of service by infected semen. Among many other symptoms, abortion is the most obvious manifestation in cattle. It has been highlighted that infection in cattle does not necessarily lead to clinical signs [4]. Diagnosis based on clinical signs cannot be generalized to all age groups, especially in non pregnant heifers and male cattle, as abortion is the main clinical feature of this infection. Therefore, a definitive diagnosis must be supported by laboratory tests that depend on the isolation of Brucella from abortion material, udder secretions or from tissues removed at post-mortem. Presumptive diagnosis can be made by assessing specific cell-mediated or serological responses to Brucella antigens.

The common serological tests used for bovine brucellosis screening are RBPT and ELISA test [5].

Rose Bengal plate test (RBPT) is based on agglutination of colored particulate antigen (killed Brucella organisms) by the antibodies present in the patient's serum [6].

Although it is a simple, cheap and effective test, the RBPT is generally considered to be less sensitive than other tests like standard tube agglutination test (STAT), complement fixation test (CFT) and ELISA [6,7]. ELISA has been claimed to be a good screening test whether used alone or in combination with the RBPT $[7,8]$. It has been reported that, in average, RBPT has a low sensitivity $(81.2 \%)$ and specificity (86.3\%) compared to the sensitivity (97.7\%) and the specificity (90.5\%) of C-ELISA and compared to the sensitivity (96\%) and the specificity (93.8\%) of the Indirect- ELISA in detecting bovine brucellosis [7].

Evidence of bovine brucellosis and its public health significance has been reported by several authors in Africa [4,5,9-11]. The disease has been reported as enzootic in Rwanda [12-14]. However, as far as we know, in Rwanda no studies have been conducted on the comparison

*Corresponding author: Rosine Manishimwe, School of Animal Sciences and Veterinary Medicine, University of Rwanda -Nyagatare Campus, Rwanda, Tel: +2507875031119; E-mail: rosinem3@yahoo.fr

Received November 01, 2014; Accepted December 29, 2014; Published December 30, 2014

Citation: Manishimwe R, Ntaganda J, Habimana R, Nishimwe K, Byukusenge M et al. (2015) Comparison between Rose Bengal Plat Test and Competitive Enzyme Linked Immunosorbent Assay to Detect Bovine Brucellosis in Kigali City, Rwanda. J Veterinar Sci Technol 6: 211. doi:10.4172/2157-7579.1000211

Copyright: ( 2015 Manishimwe $\mathrm{R}$ et al. This is an open-access article distributed under the terms of the Creative Commons Attribution License, which permits unrestricted use, distribution, and reproduction in any medium, provided the original author and source are credited. 
Citation: Manishimwe R, Ntaganda J, Habimana R, Nishimwe K, Byukusenge M, et al. (2015) Comparison between Rose Bengal Plat Test and Competitive Enzyme Linked Immunosorbent Assay to Detect Bovine Brucellosis in Kigali City, Rwanda. J Veterinar Sci Technol 6: 211. doi:10.4172/2157-7579.1000211

Page 2 of 4

of RBPT and C-ELISA in detection of Brucella antibodies in cattle even if these two tests are commonly associated during the screening of the disease $[1,5,7,15]$

The present study was therefore, undertaken to compare two serological tests (RBPT and C-ELISA test) in detection of bovine brucellosis in Kigali city.

\section{Materials and Methods}

To compare the RBPT and C-ELISA test in detecting Bovine brucellosis in Kigali city, the used data were provided by the Rwanda Agriculture Board (RAB), the unit of Veterinary Services. Data were collected during the routine countrywide disease surveillance in October 2010. During the disease surveillance, a big number of sera were collected in the whole country to detect bovine brucellosis antibodies using RBPT and C-ELISA test. Only sera collected in the capital of the country, Kigali, were used in this study.

\section{Study population and sampling}

Cattle population in the suburban areas of Kigali city was targeted by the surveillance. In the three districts (Nyarugenge, Kicukiro and Gasabo) of Kigali city, cattle farms were selected randomly with an objective of getting the maximum of farms. All cattle present in each selected farm were included in the sample. Randomly, 157 farms were selected where 2017 cattle were subjected to blood sample collection.

Blood samples were collected from either the jugular or coccygeal vein using sterile plain vacutainer tubes. Other collected information was the district where the farm is located, the farm owner, the cattle identification and the cattle's sex. Blood samples were put in cool boxes with ice and were transported to the Rwanda Agriculture Board Laboratory-unit of serology. At the laboratory blood were centrifuged. The obtained sera were aliquoted into small serum vials and stored in freezers at $-20^{\circ} \mathrm{C}$ until the time for analysis.

\section{Serology}

All collected serum samples were screened by The RBPT according the procedure described by Alton et al. (15). Briefly, the sera and antigen were brought to room temperature for $45 \mathrm{~min}$ before use. One Brucella positive and one negative reference samples were used on

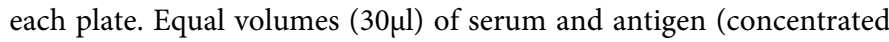
suspension of $B$. abortus, Weybridge strain 99; Institut Pourquier, France) were mixed and rotated on a glass plate for 4 minutes. Presence of agglutination was regarded as positive.All sera were also tested by the C-ELISA, SVANOVIR'Brucella-Ab C-ELISA (Svanova, Sweeden) using the protocol described by the manufacturer:

In this procedure, the samples are exposed to Brucella abortus smooth lipopolysaccaride (S-LPS) coated wells on microtiter plates together with mouse monoclonal antibody $(\mathrm{mAb})$ specific for an epitope on the o-poly-saccharide portion of the S-LPS antigen. After an incubation period the microplate is washed and goat anti mouse IgG antibody conjugate with hoseradish peroxidise (HRP) is added which binds to any mAb's bound to S-LPS on the plate. Unbound materials are removed by rinsing before the addition of the substrate solution. Color development is due to the conversion of the substrate by the conjugate. Stop solution is added and the optical density is measured by microplate photometer at $450 \mathrm{~nm}$. In the absence of antiBrucella antibody in the test serum (negative), the mAb binds to the o-polysaccharide epitope of the S-LPS antigen and is indicated by color development. If the test serum contains Brucella specific antiboies (Positive) they compete with the $\mathrm{mAb}$ for the epitope sites and inhibit the $\mathrm{mAB}$ binding to the o-poly- saccharide portion of S-LPS antigen and subsequent color development.

\section{Data analysis}

Collected information and laboratory results were entered into a Microsoft Excel spread sheet and descriptive statistics were performed.

Statistical comparisons between qualitative variables were done using the chi-square test at $p<0.05$ and the agreement between RBPT and C-ELISA in detection of bovine brucellosis in Kigali was estimated using Kappa test (when Kappa $=1$ indicates perfect agreement, whereas Kappa $=0$ indicates that there is no agreement). The Statistical Package for the Social Sciences (SPSS) version 16.0 has been used in statistical analysis.

\section{Results}

The study included 2017 cattle representing 157 Farms. Male and female cattle from the three districts of Kigali city were all represented with a high representation of female $(96.2 \%)$ as illustrated in the Table 1. All serum samples were tested by both RBPT and C-ELISA for bovine brucellosis detection.

With RBPT an overall prevalence of $2.03 \%$ was obtained while C-ELISA test gave a prevalence of $1.7 \%$. Only female were found to be infected.

The district of Kicukiro had the highest prevalence for both RBPT (4.43\%) and C-ELISA (3.94\%) while Gasabo district had the lowest prevalence $(\mathrm{RBPT}=0.78 \%$; C-ELISA $=0.52 \%)$ (Table 2$)$.

For both tests, it was noticed that the difference of prevalence across districts was statistically significant $(\mathrm{p}<0.05)$.

The comparison of the two tests in detection of bovine brucellosis has shown that all positive cattle to C-ELISA test were positive RBPT. But the other sense was not true; there were some false positives on RBPT (Table 3).

The chi square test showed that the observed difference in prevalence given by RBPT and the prevalence given by C-ELISA was significant $(\mathrm{p}<0.05)$ but the agreement between the two tests was found to be excellent because the calculated kappa test was close to $1($ Kappa $=0.92)$.

\section{Discussion}

This study revealed an overall prevalence of bovine brucellosis in Kigali of $2.03 \%$ on RBPT and $1.7 \%$ on C-ELISA test.

\begin{tabular}{|c|c|c|c|c|c|c|}
\hline \multirow{2}{*}{ Sex } & \multicolumn{3}{|c|}{ Origin (District) } & \multirow{2}{*}{ Total } & \multirow{2}{*}{ Percentage } \\
\cline { 2 - 7 } & Gemasabo & Kicukiro & Nyarugenge & & \\
\cline { 2 - 7 } & Female & 1126 & 580 & 246 & 1952 & $96.8 \%$ \\
\cline { 2 - 7 } & Male & 26 & 29 & 10 & 65 & $3.2 \%$ \\
\cline { 2 - 7 } & Total & 1152 & 609 & 256 & 2017 & \\
\cline { 2 - 7 } & Percentage & $57.1 \%$ & $30.2 \%$ & $12.7 \%$ & & \\
\hline
\end{tabular}

Table 1: Distribution of cattle in different Kigali Districts by sex.

\begin{tabular}{|c|c|c|c|c|c|}
\hline & Number of & \multicolumn{2}{|c|}{ RBPT } & \multicolumn{2}{c|}{ C-ELISA } \\
\cline { 3 - 6 } & cattle & Positive & Prevalence & Positive & Prevalence \\
\hline Gasabo & 1152 & 9 & $0.78 \%$ & 6 & $0.52 \%$ \\
\hline Kicukiro & 609 & 27 & $4.43 \%$ & 24 & $3.94 \%$ \\
\hline Nyarugenge & 256 & 5 & $1.95 \%$ & 5 & $1.95 \%$ \\
\hline Total & 2017 & 41 & $2.03 \%$ & 35 & $1.74 \%$ \\
\hline
\end{tabular}

Table 2: Prevalence of bovine brucellosis across the three districts of Kigali. 
Citation: Manishimwe R, Ntaganda J, Habimana R, Nishimwe K, Byukusenge M, et al. (2015) Comparison between Rose Bengal Plat Test and Competitive Enzyme Linked Immunosorbent Assay to Detect Bovine Brucellosis in Kigali City, Rwanda. J Veterinar Sci Technol 6: 211. doi:10.4172/2157-7579.1000211

Page 3 of 4

\begin{tabular}{|c|c|c|c|c|}
\hline \multirow{2}{*}{} & \multirow{2}{*}{} & \multicolumn{2}{|c|}{ C-ELISA } & \\
\cline { 2 - 5 } & Negative & Positive & Total \\
\cline { 2 - 5 } & Negative & 1976 & 0 & 1976 \\
\hline \multirow{2}{*}{ RBPT } & Positive & 6 & 35 & 41 \\
\hline & Total & 1982 & 35 & 2017 \\
\hline
\end{tabular}

Table 3: The Comparison of RBPT and C-ELISA results.

These results contrast with results reported in the eastern province of Rwanda, Nyagatare district, where the prevalence was $9.9 \%$ (12), and the results reported in cattle from Kabutare farm's abattoir in the southern province where the prevalence of $7.4 \%$ has been found [13]. The prevalence in Kigali city was lower than the prevalence of $4.7 \%$ by RBPT and 3.34\% by I-ELISA in Luwero district in Uganda [9].

The intensive rearing system, where disease control measures are highly applied, is the main rearing system found in cattle farms in Kigali city [16]. The declining trend of bovine brucellosis in cattle from Kigali city may be the result of high control efforts in selected farms.

The study has shown that RBPT has given a greater prevalence than C-ELISA test. This is different from results reported in Mosul city, in Iraq where C-ELISA had given a greater prevalence than RBPT [17].

RBPT may produce false-positive results due to $B$. abortus S19 vaccination or exposure to gram-negative bacteria that have lipopolysaccharide (LPS) O-chains similar to those of brucellae, which include Vibrio cholerae O1, E. coli O:157, Salmonella group N (O:30) and Yersinia enterocolitica O:9 $[1,7,18]$. RBPT is unable to distinguish between $B$. abortus strain 19 vaccinated animals and naturally infected animals.

Thus, C-ELISA was developed to overcome this problem. It is capable of distinguishing vaccinated animals or animals infected with cross-reacting organisms from naturally infected animals, thereby reducing the number of false-positive reactions [1,7].

Although the difference of prevalence by the two tests was found to be statistically significant, the agreement between the two test was excellent (Kappa=0.92). A study done in Iraq has revealed similar results: there was a significant difference between the prevalence of brucellosis in sheep given by RBPT and the prevalence given by C-ELISA, even if the agreement between the two tests has been found good, with a Kappa value of 0.71 [19].

This study has given results that consistent with findings from a study conducted in Sudan, where the agreement between RBPT and C-ELISA was excellent with a Kappa of 0.86 [20].

In India, close results have been reported where the agreement between the two tests was very good with a Kappa value of 0.72 [21]. However in a study done in Iran, a bad agreement between the two tests, with a kappa value of 0.353 , has been reported [17].

For a better assessment of the situation of brucellosis in cattle, it is recommended to use C-ELISA over RBPT [7,22] to eliminate false positive results amongst positive sera [23].

This study has given an insight on the agreement between the two serological tests commonly used to detect bovine brucellosis in Kigali city. As the agreement between two tests varies depending on the prevalence [24] the study should be extended to other provinces of Rwanda where the prevalence is probably different to the prevalence in Kigali.

\section{Acknowledgments}

The authors are very grateful to the Rwanda Agriculture Board, the Ministry of Agriculture and Animal resources for their collaboration.

\section{References}

1. OIE (2009) Bovine brucellosis. OIE Terrestrial Manual. OIE- The World Organization for Animal Health. Paris France.

2. Halling SM, Young EJ (1994) Chapter 3 - Brucella. In: Hui YH, Gorham JR, Murrell KD, and Cliver DO (eds.). Foodborne Disease Handbook - Disease caused by Bacteria. Marcel Dekker, Inc, New York: 63-69.

3. Cork SC. and Checkley S (2010) Zoonotic pathogens in the food chain. CABI, Wallingford.

4. Akakpo AJ, Bornarel P (1987) Epidemiology of brucelloses animales in tropica Africa: Clinical investigations, serological and bacteriological. Rev. Sci. Tech. Off. Int. Epiz 6: 981-1027

5. Kashiwazaki Y, Ecewu E, Imaligat JO, Mawejje R, Kirunda M, et al. (2012) Epidemiology of Bovine Brucellosis by a Combination of Rose Bengal Test and Indirect ELISA in the Five Districts of Uganda. J. Vet. Med. Sci. 74: 1417-1422

6. Chachra D, Saxena HM, Kaur G, Chandra M (2009) Comparative efficacy of Rose Bengal plate test, standard tube agglutination test and Dot ELISA in immunological detection of antibodies to Brucella abortus in sera. Journal of Bacteriology Research 1: 030-033.

7. Gall D, Nielsen K (2004) Serological diagnosis of bovine brucellosis: a review of test performance and cost comparison. Rev. sci. tech. Off. int. Epiz., 23 : 989-1002.

8. Jacques I, Bernardin VO, Dubray G (1998) Efficacy of ELISA compared to conventional tests (RBPT and CFT) for the diagnosis of Brucella melitensis infection in sheep. Vet. Microbiol. 64: 61 - 73.

9. Nizeyimana G, Mwiine FN, Ayebazibwe C (2013) Comparative Brucella abortus antibody prevalence in cattle under contrasting husbandry practices in Uganda. Journal of the South African Veterinary Association 84: 1-5.

10. Junaidu AU, Garba HS (2006) Application of Competitive Elisa (Compelisa) Rose Bengal Plate Test (RBPT) and Serum Agglutination Test (SAT) for Detection of Antibodies to Brucella Infection in Slaughter Cattle in Sokoto, Nigeria. Sahel J. Vet. Sci. 5: 9-12.

11. Mangen MJ, Otte J, Pfeiffer D, Chilonda P (2002) Bovine brucellosis in SubSaharan Africa: Estimation of sero-prevalence and impact on meat and milk offtake potential Food and Agriculture Organization Livestock Information and Policy Branch, AGAL. Livestock Policy Discussion Paper No. 8.

12. Chatikobo P, Manzi M, Kagarama J, Rwemarika JD, Umunezero O (2008) The prevalence of bovine brucellosis in milking dairy herds in Nyagatare and its implications on dairy productivity and public health. The 3rd International Conference on Appropriate Technology (3rd ICAT).

13. Rujeni N, Mbanzamihigo L (2014) Prevalence of brucellosis among women presenting with abortion/stillbirth in Huye, Rwanda. Journal of Tropical Medicin 2014: 1-3

14. Akakpo JA, Ndour Apn (2013) Bovine brucellosis in West and Central Africa: current status. African Journal of Animal Production and Health, 11: 23-28.

15. Alton GG, Jones LM, Pietz DE (1975) Bacteriological methods. In Laboratory techniques in brucellosis, 2nd Ed. World Health Organization, Geneva.

16. Butera JB, Rutagwenda T (2004) Strategic Transformation of Agriculture in Rwanda. Animal sub -sector production. Expert group, Consulting and Development Support. Ministry Of Agriculture And Animal Resources, Kigali, Rwanda.

17. Iraqi OMA, Kh.Al-Hankawe O, Abdul-Majeed MO, Al-Farwachi MI (2009) Comparison between competitive ELISA and Rose-bengal tests in detection of brucella antibodies in buffalo sera in Mosul city, Iraq. Bas J Vet Res 8:93.

18. Munoz PM, Marin CM, Monreal D, Gonzalez D, Garin-Bastuji B, et al.(2005) Efficacy of several serological tests and antigens for diagnosis of bovine brucellosis in the presence of false-positive serological results due to Yersinia enterocolitica O:9. Clin Diag Lab Immunol, 12: 141-151.

19. Al-Hankawe OKH, Rhaymah MS (2012) Comparison between ELISA and other serological tests for diagnosis of brucellosis in sheep in Ninevah Province. Iraq Journal of Veterinary Sciences. 2:75 
Citation: Manishimwe R, Ntaganda J, Habimana R, Nishimwe K, Byukusenge M, et al. (2015) Comparison between Rose Bengal Plat Test and Competitive Enzyme Linked Immunosorbent Assay to Detect Bovine Brucellosis in Kigali City, Rwanda. J Veterinar Sci Technol 6: 211. doi:10.4172/2157-7579.1000211

Page 4 of 4

20. Adil MAS, Hind AEN (2012) Evaluation of four serological tests to detect prevalence of bovine brucellosis in Khartoum State. Journal of Cell and Animal Biology 6:140-143.

21. Islam MRUL, Pratap Gupta M, Kaur P (2013) Comparative evaluation of indirect enzyme linked immunosorbent assay, rose bengal plate test, microagglutination test, and polymerase chain reaction for diagnosis of brucellosis in buffaloes. Turk J Vet Anim Sci 37: 306-310.

22. Erdenebaatar J, Bayarsaikhan B, Yondondorj A, Watarai M, Shirahata T, et al.
(2004) Epidemiological and serological survey of Brucellosis in Mongolia by ELISA using sarcosine extracts. Microbiology Immunology 48: 571-77.

23. Chand P, Sharma AK (2004) Situation of brucellosis in bovines at organized cattle farms belonging to three different states. Journal of Immunology and Immunopathology 6: 11-15.

24. Sim J, Wright Chris C (2005) The Kappa Statistic in Reliability Studies: Use, Interpretation, and Sample Size Requirements. Physical Therapy 85: 257-268. 